\title{
BMJ open Antiviral therapy for prevention of hepatocellular carcinoma in chronic hepatitis C: systematic review
and meta-analysis of randomised
controlled trials
}

Nina Kimer, ${ }^{1}$ Emilie Kristine Dahl, ${ }^{1}$ Lise Lotte Gluud, ${ }^{2}$ Aleksander $\mathrm{Krag}^{1,2}$

To cite: Kimer N, Dahl EK, Gluud LL, et al. Antiviral therapy for prevention of hepatocellular carcinoma in chronic hepatitis C: systematic review and meta-analysis of randomised controlled trials. BMJ Open 2012;2:e001313.

doi:10.1136/bmjopen-2012001313

- Prepublication history and additional material for this paper are available online. To view these files please visit the journal online (http://dx.doi.org/10.1136/ bmjopen-2012-001313).

Received 16 April 2012 Accepted 5 October 2012

This final article is available for use under the terms of the Creative Commons Attribution Non-Commercial 2.0 Licence; see http://bmjopen.bmj.com

${ }^{1}$ Department of Medical Gastroenterology, Copenhagen University Hospital Hvidovre, Hvidovre, Denmark

${ }^{2}$ Department of Internal Medicine, Copenhagen University Hospital Gentofte, Hellerup, Denmark

Correspondence to Dr Nina Kimer; nina.kimer@regionh.dk

\section{ABSTRACT}

Objectives: To determine whether antiviral therapy reduces the risk of developing hepatocellular carcinoma (HCC) in chronic hepatitis C.

Design: Systematic review and meta-analyses of randomised controlled trials. Prospective cohort studies were included in sensitivity analyses.

Data Sources: Eligible trials were identified through electronic and manual searches.

Study Selection: Eight randomised controlled trials comparing antiviral therapy (interferon or pegylated interferon alone or with ribavirin) versus placebo or no intervention were included.

Data extraction and synthesis: Two independent reviewers assessed the methodological quality of studies and extracted data. Random effects meta-analyses were performed. Subgroup, sensitivity, regression and sequential analyses were performed to evaluate sources of intertrial heterogeneity, the risk of bias and the robustness of the results after adjusting for multiple testing.

Results: Random effects meta-analysis showed that antiviral therapy reduced the risk of HCC $(81 / 1156$ vs $129 / 1174$; risk ratio $0.53,95 \% \mathrm{Cl} 0.34$ to 0.81 ). In subgroup analyses, antiviral therapy was more beneficial (test for subgroup differences $p=0.03$ ) in virological responders $(0.15,0.05$ to 0.45$)$ than in nonresponders $(0.57 ; 0.37$ to 0.85$)$. No evidence of bias was seen in regression analyses. Sequential analysis confirmed the overall result. The sensitivity analyses showed that the cohort studies found that antiviral therapy reduced the risk of HCC. There was clear statistical evidence of bias in the cohort studies $(p=0.02)$.

Conclusions: Antiviral therapy may reduce the risk of HCC in hepatitis C-related fibrosis and cirrhosis. The effect may be seen irrespective of the virological response, but is more pronounced among virological responders compared with non-responders.

\section{INTRODUCTION}

Worldwide, hepatocellular carcinoma (HCC) is one of the most common malignant

\section{ARTICLE SUMMARY}

Article focus

- To determine whether antiviral therapy reduces the risk of developing hepatocellular carcinoma (HCC) in chronic hepatitis C.

\section{Key messages}

- Antiviral therapy reduces the risk of HCC.

- The preventive effect of antiviral therapy on the development of HCC is seen irrespective of the antiviral response (loss of hepatitis $\mathrm{C}$ virus RNA), but is more pronounced among patients who are virological responders.

Strengths and limitations of this study

- The review only addresses interferon as monotherapy.

- No points on dose and duration can be made on the available data.

- HCC incidence is diminished in both virological responders and non-responders.

- A thorough systematic review and meta-analysis provide confidence in the findings.

diseases accounting for approximately $90 \%$ of primary liver cancers. ${ }^{1}{ }^{2}$ Hepatitis $\mathrm{C}$ and cirrhosis are two of the most important risk factors for the development of HCC. ${ }^{3}$ Among patients with hepatitis C-related cirrhosis the estimated annual incidence of HCG ranges from $1 \%$ to $4 \%^{1}$ depending on the severity of the underlying liver disease and ethnicity of the patient. ${ }^{14}$

Hepatitis $\mathrm{C}$ is an insidious disease that often leads to chronic infection. Few patients clear the virus spontaneously. Antiviral Therapy for patients with chronic hepatitis $\mathrm{C}$ may lead to a sustained loss of the virus. ${ }^{5}{ }^{6} \mathrm{~A}$ number of patients with an initial response relapse within a few months after treatment. For patients who achieve a 24-week sustained virological response (SVR), the risk of relapse is 
negligible. ${ }^{7}$ The proportion of patients who achieve a virological response depends on the underlying viral genotype and on the type of therapy. Interferon was introduced in 1986 and initially used as monotherapy. ${ }^{8}$ Subsequent trials showed that the addition of ribavirin and the use of a pegylated form of interferon increased the number of sustained virological responders. ${ }^{5} 6910$ The effect of antiviral therapy on clinical outcome measures is debated. Some studies have found that interferon increases survival and reduces the incidence of HCC. ${ }^{11-13}$ Some data also suggest a reduction in HCC in nonsustained responders. ${ }^{14}$ Whether a SVR is the key factor leading to a reduced risk of developing HCC is not known. Other studies and randomised trials as well as systematic reviews did not find beneficial effects of antiviral therapy on mortality or morbidity. ${ }^{15} 16$

\section{METHODS}

The main objective of the present review was to determine the effect of antiviral therapy versus placebo or no intervention for the prevention of HCC in hepatitis C-related cirrhosis or fibrosis, and to assess the importance of virological response to treatment in relation to risk of HCC.

The review was carried and reported out based on a protocol developed using the methods described in the Cochrane Handbook for Systematic Reviews of Interventions and the PRISMA (Preferred Reporting Items for Systematic Reviews and Meta-analyses) Statement for Reporting Systematic Reviews and Meta-analysis. ${ }^{17} 18$

Trials on patients with hepatitis C-related cirrhosis or fibrosis treated with antiviral therapy were included if reporting any of the outcome measures assessed. Our primary analyses included randomised controlled trials. Prospective cohort studies with defined control groups were included in sensitivity analyses. Trials were included irrespective of language or publication status. The dose, type and duration of therapy were not considered in the inclusion criteria. Trials on interferon or pegylated interferon alone or with ribavirin were eligible for inclusion. Trials on patients with HIV and patients with chronic hepatitis B were excluded. The primary outcome measure was HCC. Secondary outcomes were overall mortality, HCC-related mortality, liver-related mortality (defined as death following variceal bleeding, hepatorenal syndrome, liver failure or spontaneous bacterial peritonitis) and liverrelated morbidity (variceal bleeding, hepatorenal syndrome, liver failure or spontaneous bacterial peritonitis).

Two authors (NK and AK) participated in the literature searches. Excluded trials were listed with the reason for exclusion. Two authors (NK and ED) performed independent standardised data extraction. Extracted data were validated by two authors (AK and LG).

\section{Search strategy identification of eligible trials}

Eligible trials were identified through electronic searches of the Cochrane Library (issue 3, 2012), PubMed (1966 -August 2012), EMBASE (1955-August 2012) and Web of Science (1900-August 2012). Additional searches were performed including scanning of reference lists from relevant papers on chronic hepatitis C and HCC, conference proceedings and the World Health Organization Trial Search Portal (www.who.int/ trialsearch/). All authors were contacted by email with enquiries of additional data.

\section{Assessment of bias control}

The quality of bias control was assessed through individual components. ${ }^{17}$ Based on previous evidence, ${ }^{19}$ our primary assessment of bias control was based on the randomisation methods including the allocation sequence generation (classed as adequate if based on a table of random numbers or similar) or allocation concealment (classed as adequate if based on a central independent unit or similar). Trials in which randomisation methods were classed as adequate were defined as having a low risk of bias. Additional components included blinding (performance bias and detection bias), handling of missing outcome data (attrition bias) and selective reporting (reporting bias). We also extracted sample size calculations and whether the sample size was reached or the trial was terminated prematurely. Due to the risk of selection bias associated with the observational design, all cohort studies were classed as having a high risk of bias.

\section{Statistical analysis}

The analyses were performed using Revman V.5.1 (Nordic Cochrane Centre, Copenhagen), STATA V.11 (STATA Corp, College Station, Texas, USA) and TSA V.9 (Copenhagen Trial Unit, Copenhagen, Denmark). The primary meta-analyses were performed using random effect models due to an expected clinical heterogeneity (differences between patient and intervention characteristics).The results of the analyses were presented as risk ratios with $95 \% \mathrm{CI}$ and $\mathrm{I}^{2}$ as a marker of intertrial heterogeneity. We defined $\mathrm{I}^{2}$ values between $30 \%$ and $60 \%$ as moderate heterogeneity and values $>60 \%$ as substantial heterogeneity. The number needed to treat was calculated as the inverse of the risk difference. Fixed effect meta-analyses were performed to evaluate the robustness of the results. The results were only reported if the overall conclusion differed from the result of the random effects meta-analysis. To evaluate the risk of bias and the influence of patient characteristics, the results of the analysis was analysed after exclusion of trials without adequate randomisation and trials including patients with fibrosis. The risk of bias and small study effects was assessed through regression analyses (Egger's test). Planned subgroup analyses evaluated the effect of virological response (virological responders compared with non-responders). Differences between subgroups were analysed using the test of subgroup differences and the results expressed using the $\mathrm{p}$ values. ${ }^{20}$ A sequential analysis was performed to adjust for the risk of false-positive findings due to repeated tests. ${ }^{21}$ The sequential analysis 
was performed for the primary random effects meta-analysis. Based on the results of the primary meta-analysis, the incidence in the control group was set to $12 \%$ and the relative risk reduction to $41 \%$. The heterogeneity correction was set to $64 \%$ (model-based), power to $80 \%$ and $\alpha$ to $5 \%$.

\section{RESULTS}

\section{Study selection}

The electronic searches generated 1711 references (figure 1). After reading the titles and abstracts, we identified 26 potentially relevant randomised controlled trials and observational studies described in 27 references. Fourteen additional trials and references were identified through the manual searches. Twenty-four references were retrospective cohort studies, case-control studies or trials that did not assess the risk of HCC. Eight randomised trials, ${ }^{15}{ }^{22-28}$ and five prospective cohort studies ${ }^{29-33}$ were included in our analyses.

\section{Characteristics of included trials and patients}

All trials were published in English as full paper articles. The trials were conducted in France, Italy, Spain, Japan and USA. All patients underwent ultrasound, serological testing and a liver biopsy at baseline. The diagnosis of chronic hepatitis $\mathrm{C}$ was based on hepatitis $\mathrm{C}$ virus RNA for at least 6 months and active hepatitis on liver histology. Two randomised trials included patients with cirrhosis or fibrosis (table 1). The remaining trials included patients with cirrhosis. Two randomised trials assessed pegylated interferon ${ }^{15} 25$ and one assessed interferon plus ribavirin. ${ }^{22}$ The remaining trials assessed interferon monotherapy. All control groups received no intervention. The duration of therapy varied from 1 to 5 years and the duration of follow-up ranged from 2 to 8.7 years. The observational studies compared interferon versus no intervention for patients with cirrhosis. The duration of therapy ranged from 0.5 to 1.5 years and the duration of follow-up from 5 to 7 years.

\section{Risk of bias}

Randomisation methods (allocation sequence generation and allocation concealment) were classified as adequate in six trials. ${ }^{15} 22 \quad 24-2628$ Two trials did not describe how the allocation sequence was generated or the allocation sequence was concealed. None of the trials found discrepancies between baseline patient characteristics in the intervention versus control group. None of the included trials were blinded. No clear evidence of reporting or attrition bias was identified. Five trials reported sample size calculations and that the planned sample size was achieved. ${ }^{15}$ 24-26 28 Two trials were registered in clinical trial databases 3 months after the enrolment of the first patient and before the completion of the trial. ${ }^{1525}$

\section{Intervention effects: HCC}

In total, 81 of 1156 patients randomised to antiviral therapy and 129 of 1074 patients in the control group developed HCC. Random effects meta-analysis showed that antiviral therapy reduced the risk of HCC (RR 0.53, $95 \%$ CI 0.34 to $0.81 ; \mathrm{I}^{2} 50 \%$; figure 2 ). The corresponding number needed to treat to prevent one case of HCC was eight patients. There was no evidence of bias or small study effects in regression analysis (Egger's test $\mathrm{p}=0.931$ ). The sequential analysis revealed that the cumulative Z-curve crossed the monitoring boundary, which confirmed the overall result after adjusting for multiple testing. Similar results were achieved after exclusion of trials without adequate randomisation which confirmed the overall result (RR $0.58,95 \%$ CI 0.37 to 0.95 ) and trials on patients with fibrosis (RR $0.51,95 \%$ CI 0.34 to 0.77$)$. In subgroup analysis (figure 3), the effect of antiviral therapy was more pronounced (test for subgroup differences $\mathrm{p}=0.03$ ) among patients with a virological response (RR 0.15 , 95\% CI 0.05 to 0.45 , Egger's test $p=0.543$ ) compared with virological non-responders (RR $0.57 ; 95 \% \quad 0.37$ to 0.85 , Egger's test $\mathrm{p}=0.425$ ).
Figure 1 Study selection flow chart.

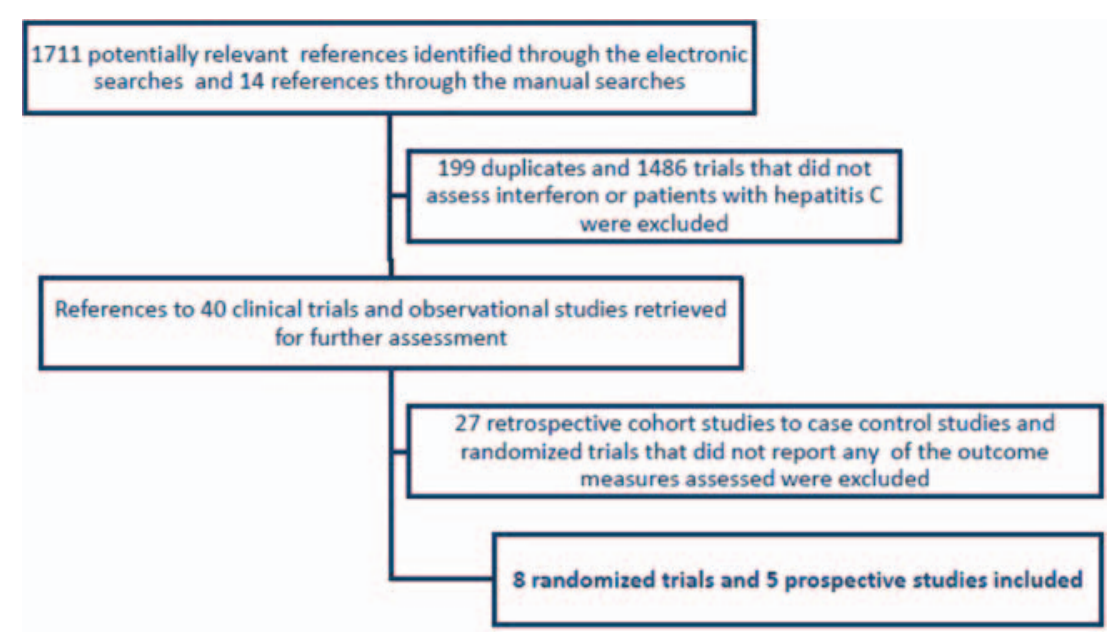


Table 1 Characteristics of randomised controlled trials and cohort studies

\begin{tabular}{|c|c|c|c|c|c|}
\hline Trial & $\begin{array}{l}\text { Proportion } \\
\text { of patients } \\
\text { with cirrhosis } \\
\text { at baseline (\%) }\end{array}$ & $\begin{array}{l}\text { Antiviral therapy } \\
\text { administered }\end{array}$ & $\begin{array}{l}\text { Duration of } \\
\text { treatment }\end{array}$ & $\begin{array}{l}\text { Maximum duration } \\
\text { of follow-up }\end{array}$ & $\begin{array}{l}\text { Total number } \\
\text { of patients }\end{array}$ \\
\hline \multicolumn{6}{|c|}{ Randomised controlled trials } \\
\hline Azzaroli $2004^{22}$ & 100 & $\begin{array}{l}\text { Interferon } \alpha \text { plus } \\
\text { ribavirin }\end{array}$ & $1-2$ years & 5 years & 101 \\
\hline Fartoux $2007^{24}$ & 100 & Interferon & 2 years & 2 years & 102 \\
\hline Lok $2011^{25}$ & 41 & Pegylated interferon & 3.5 years & 8.7 years & 1048 \\
\hline Nishiguchi $2001^{26}$ & 100 & Interferon & 2 years & 8.7 years & 90 \\
\hline Soga $2005^{27}$ & 0 & Interferon & Unclear & 5 years & 133 \\
\hline Valla $1999^{28}$ & 100 & Interferon & 1 year & 4.8 years & 99 \\
\hline Serfaty $1998^{32}$ & 100 & Interferon & $0.5-1.5$ years & 6 years & 103 \\
\hline Shiratory $2005^{33}$ & 100 & Interferon & 39 weeks* & 5 years & 345 \\
\hline
\end{tabular}

Sensitivity analyses were performed to evaluate the results of the observational studies. In agreement with our primary analyses, the observational studies found that antiviral therapy reduces the risk of developing HCC (RR $0.2995 \%$ CI 0.12 to 0.69 ) (figure 2). The analysis also found a higher degree of heterogeneity among observational studies $\left(\mathrm{I}^{2} 75 \%\right)$ than among randomised trials $(33 \%)$. Regression analysis showed clear evidence of bias in the observational studies (Egger's test $\mathrm{p}=0.02$ ).

\section{Intervention effects: mortality and liver-related} complications

Four randomised trials reported all-cause mortality. $^{15} 252628$ Random effects meta-analysis found no clear difference between the intervention and control group (93/918 vs 90/932; RR $0.81,95 \%$ CI 0.33 to 2.03; $\mathrm{I}^{2} 84 \%$; Egger's test $\left.\mathrm{p}=0.348\right)$. No beneficial or detrimental effects were identified when analysing liver-related mortality (RR $0.71,95 \%$ CI 0.2 to 2.51 ; I ${ }^{2} 74 \%$; Egger's test $\mathrm{p}=0.59$, four trials) or liver-related morbidity (34/400 vs $42 / 389$, RR $0.73,95 \%$ CI 0.48 to $1.11, \mathrm{I}^{2} 0 \%$; Egger's test $\mathrm{p}=0.306$ ).

\section{DISCUSSION}

This review found that antiviral therapy may prevent HCC in patients with hepatitis C-related fibrosis or cirrhosis. The size of the effect was clinically relevant with a number needed to treat of eight patients after a median of 5 years. Based on the relatively high event rates, the underlying prognosis of the included patients may differ from the patient population in some clinical settings. However, after considering the risk of detection or ascertainment bias the size of the effect was clinically relevant. The evidence concerning all-cause and liverrelated mortality and morbidity was less convincing. Additional evidence is needed to assess these outcome measures.

Our subgroup analyses suggest that the antiviral therapy may have beneficial effects on the risk of developing HCC that are unrelated to the virological response. Although the intervention was more beneficial among sustained virological responders than nonresponders, there was a clear effect in both patient groups. A former review ${ }^{14}$ reached similar conclusions, but included randomised controlled trials and observational studies in their overall analysis.

The assessment of intervention effects on clinical outcome measures is difficult to assess in trials of a diseases with a protracted course. Complications to hepatitis $\mathrm{C}$ including cirrhosis and HCC takes years to develop. $^{34}$

We originally planned to include observational studies in sensitivity analysis because we expected that the randomised controlled trials would be too small or have insufficient follow-up. We were surprised to find that the duration of follow-up was slightly longer in the randomised trials than in the observational studies. Likewise, the statistical power of the randomised trials was not weaker than the observational studies. Since we also found a high degree of heterogeneity and evidence of bias in the observational studies, the result of these studies should only be used with caution. Our findings do not support the inclusion of non-randomised studies in systematic reviews on viral hepatitis.

Only two of the included trials evaluated pegylated interferon, which is the current standard treatment for chronic hepatitis C. ${ }^{7}$ Two studies have found that 
Figure 2 Random effects meta-analysis of randomised trials and cohort studies on antiviral therapy versus no intervention for development of hepatocellular carcinoma (HCC) in hepatitis C-related cirrhosis or fibrosis.
Risk Ratio

Random effects to $95 \% \mathrm{Cl}$

\begin{tabular}{|c|c|}
\hline \multicolumn{2}{|c|}{ Randomized controlled trials } \\
\hline Azzaroli 2004 & $0.16(0.04$ to 0.70$)$ \\
\hline Bemardinello 1999 & $1.21(0.12$ to 12.62$)$ \\
\hline Bruix 2011 & $0.93(0.43$ to 2.02$)$ \\
\hline Fartoux 2007 & $1.00(0.35$ to 2.89$)$ \\
\hline $\begin{array}{l}\text { Lok } 2011 \\
\text { Nishiguchi } 2001 \\
\text { Soga } 2005\end{array}$ & $\begin{array}{l}0.75(0.50 \text { to } 1.13) \\
0.36(0.22 \text { to } 0.61) \\
0.21(0.07 \text { to } 0.81)\end{array}$ \\
\hline $\begin{array}{l}\text { Valla } 1999 \\
\text { Subtotal }(95 \% \mathrm{CI})\end{array}$ & $\begin{array}{l}0.50(0.18 \text { to } 1.39) \\
0.53(0.34 \text { to } 0.81)\end{array}$ \\
\hline \multicolumn{2}{|c|}{ Heterogeneity: $l^{2}=50 \%$} \\
\hline \multicolumn{2}{|c|}{ Test for overall effect: $P=0.004$. Egger's test $p=0.93$} \\
\hline \multicolumn{2}{|l|}{ Cohort studies } \\
\hline Bruno 1997 & $0.02(0.00$ to 0.36$)$ \\
\hline Gramenzi 2001 & $0.32(0.13$ to 0.74$)$ \\
\hline $\begin{array}{l}\text { Mazzella } 1996 \\
\text { Serfaty } 1998\end{array}$ & $\begin{array}{l}0.26(0.09 \text { to } 0.77) \\
0.22(0.07 \text { to } 0.77)\end{array}$ \\
\hline $\begin{array}{l}\text { Shiratori } 2005 \\
\text { Subtotal }(95 \% \mathrm{CI})\end{array}$ & $\begin{array}{l}0.66(0.49 \text { to } 0.88) \\
0.29(0.12 \text { to } 0.69)\end{array}$ \\
\hline \multicolumn{2}{|c|}{$\begin{array}{l}\text { Heterogeneity: } F^{2}=75 \% \\
\text { Test for overall effect: } P=0.005 \text {. Egger's test } P=0.015\end{array}$} \\
\hline Total $(95 \% \mathrm{CI})$ & $0.46(0.32$ to 0.64$)$ \\
\hline \multicolumn{2}{|c|}{ Heterogeneity: $l^{2}=58 \%$} \\
\hline Test for overall effect: & $<000001$ \\
\hline
\end{tabular}

Test for subgroup differences: $p=0.22, l^{2}=32.3 \%$
Risk Ratio Random effects to $95 \% \mathrm{Cl}$

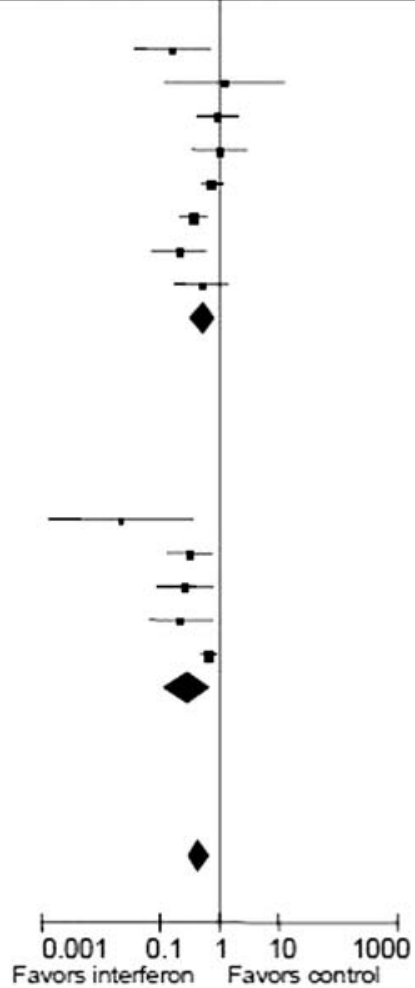

prolonged treatment with interferon reduces inflammation in the liver ${ }^{24} 35$ and improve the proportion of patients who achieve a SVR. ${ }^{36}$ The duration of treatment in some of our included trials was relatively long, which may increase the proportion of responders.
Unfortunately, we were unable to perform subgroup analyses on treatment duration or dose due to the variation in these parameters across trials. Our data provide no information on the best standard for duration of treatment or dose.
Figure 3 Random effects meta-analysis of randomised trials on antiviral therapy versus no intervention for prevention of hepatocellular carcinoma (HCC) among subgroups of sustained virological responders and non-responders.
Risk Ratio

Random effects to $95 \% \mathrm{Cl}$

Risk Ratio Random effects to $95 \% \mathrm{C}$

Virological responders to interferon versus no intervention

Azzaroli 2004

0.18 (0.01 to 2.82

Nishiguchi 2001

$0.18(0.05$ to 0.67$)$

$0.05(0.00$ to 0.85$)$

Soga 2005

Total $(95 \% \mathrm{Cl})$

$0.15(0.05$ to 0.45$)$

Heterogeneity: $r^{2}=0 \%$

Test for overall effect: $p=0.0006$ )

Virological nonresponders versus no intervention

Azzaroli 2004

0.20 ( 0.05 to 0.86$)$

Bruix 2011

$0.93(0.43$ to 2.02$)$

Lok 201

Nishiguchi 2001

$0.75(0.50$ to 1.13$)$

Soga 2005

$0.45(0.27$ to 0.78$)$

Subtotal $(95 \% \mathrm{Cl})$

$0.34(0.12$ to 0.98$)$

$0.57(0.37$ to 0.85$)$

Heterogeneity: $I^{2}=41 \%$

Test for overall effect: $p=0.007$ )

Test for subgroup differences: $\mathrm{Chi}^{2}=4.99$ to $\mathrm{df}=1(\mathrm{P}=0.03)$ to $\mathrm{I}^{2}=79.9 \%$ 
As expected, we found clinical heterogeneity between trials. The differences between trials were related to the type of intervention regimens and patient inclusion criteria.

Most of the included trials assessed interferon monotherapy. Standard practise is pegylated interferon and ribavirin in combination, ${ }^{7}$ and direct extrapolation of the observed effects to clinical practise is difficult. The protection from HCC might be even better among patients in current antiviral therapy since the proportion of virological responders continues to increase with ongoing improvements in therapy. ${ }^{1}$ Also, today's patients are diagnosed and treated earlier in the course of their disease.

Chronic inflammation of the liver is critical to the development of HCC. ${ }^{37}$ Hepatitis C patients with cirrhosis or fibrosis are likely to have a higher degree of chronic inflammation than patients without these histological changes. It is therefore likely that patients without fibrosis or cirrhosis have a smaller benefit of antiviral therapy than the patient population included in our analyses. The number needed to treat may therefore be higher.

During recent years, large randomised trials with longterm follow-up and adequate bias control have been published. The overall result of this meta-analysis was that interferon reduces the risk of HCC. Our results add to previous evidence by showing that the reduced risk of HCC is stable when assessed in randomised trials with long-term follow-up. The increased internal validity that is achieved when the results are based on trials with a higher degree of bias control supports the extent to which the overall results may be extrapolated to clinical practise.

The development of HCC involves inflammatory mediators, which promote liver cancer by compensatory proliferation of hepatocytes in response to tissue damage. ${ }^{37}$ Experimental models show that the cytokine interferon- $\gamma$ suppresses chemical carcinogenesis in hepatocytes in spite of concomitant liver injury. Prolonged treatment with interferon reduces inflammation in the liver. ${ }^{24} 35$ The potential anticarcinogenic effect of interferon could be related to its immunoregulatory and antitumoral effects. The combined evidence suggests that interferon may have other beneficial effects than the direct antiviral activity. Based on the duration of follow-up and the lack of clear evidence concerning morbidity or mortality, we cannot exclude that interferon delays rather than prevents carcinogenesis. Additional randomised trials with longer follow-up are still warranted to determine whether this is the case.

Contributors AK conceived the present review and developed the overall design with LG. NK and ED extracted data. AK and LG validated the data extraction. NK and LG performed the statistical analyses and all authors participated in the interpretation of the overall results. NK and LG drafted the protocol and review and all authors participated in the critical revision for important intellectual content. All authors have read and approved of the final version of the protocol and paper. NK had full access to all of the data in the study and takes responsibility for the integrity of the data and the accuracy of data analysis and had the final responsibility for the decision to submit for publication.

Funding This research received no specific grant from any funding agency in the public, commercial or not-for-profit sectors.

Competing interests None.

Provenance and peer review Not commissioned; externally peer reviewed.

Data sharing statement All original data extraction is available from the corresponding author.

\section{REFERENCES}

1. El-Serag HB. Epidemiology of viral hepatitis and hepatocellular carcinoma. Gastroenterology 2012;142:1264-73.

2. Parkin DM, Bray F, Ferlay J, et al. Global cancer statistics, 2002 CA Cancer J Clin 2005;55:74-108.

3. Blum HE. Does hepatitis $C$ virus cause hepatocellular carcinoma? Hepatology 1994;19:251-5.

4. Fattovich G, Stroffolini T, Zagni I, et al. Hepatocellular carcinoma in cirrhosis: incidence and risk factors. Gastroenterology 2004;127: S35-50.

5. Manns MP, McHutchison JG, Gordon SC, et al. Peginterferon alfa-2b plus ribavirin compared with interferon alfa-2b plus ribavirin for initial treatment of chronic hepatitis C: a randomised trial. Lancet 2001;358:958-65

6. Manns MP, Wedemeyer $\mathrm{H}$, Cornberg M. Treating viral hepatitis $\mathrm{C}$ : efficacy, side effects, and complications. Gut 2006;55:1350-9.

7. Craxi A, Pawlotsky JM, Wedemeyer H, et al. EASL Clinical Practice Guideline: management of hepatitis $\mathrm{C}$ virus infection. J Hepatol 2011;55:245-64.

8. Hoofnagle $\mathrm{JH}$, Mullen $\mathrm{KD}$, Jones $\mathrm{DB}$, et al. Treatment of chronic non-A, non-B hepatitis with recombinant human alpha interferon. A preliminary report. N Engl J Med 1986;315:1575-8.

9. Brok J, Gluud LL, Gluud C. Ribavirin plus interferon versus interferon for chronic hepatitis C. Cochrane Database Syst Rev 2005;3: CD005445.

10. Simin M, Brok J, Stimac D, et al. Cochrane systematic review: pegylated interferon plus ribavirin vs. interferon plus ribavirin for chronic hepatitis C. Aliment Pharmacol Ther 2007:25:1153-62.

11. Niederau $C$, Lange $S$, Heintges $T$, et al. Prognosis of chronic hepatitis C: results of a large, prospective cohort study. Hepatology 1998;28:1687-95

12. Licata A, Di BD, Schepis F, et al. When and how to treat acute hepatitis C? J Hepatol 2003;39:1056-62.

13. Miyake $\mathrm{Y}$, Iwasaki $\mathrm{Y}$, Yamamoto K. Meta-analysis: reduced incidence of hepatocellular carcinoma in patients not responding to interferon therapy of chronic hepatitis C. Int J Cancer 2010;127:989-96.

14. Singal AK, Singh A, Jaganmohan S, et al. Antiviral therapy reduces risk of hepatocellular carcinoma in patients with hepatitis C virus-related cirrhosis. Clin Gastroenterol Hepatol 2010;8:192-9.

15. Bruix J, Poynard T, Colombo M, et al. Maintenance therapy with peginterferon alfa-2b does not prevent hepatocellular carcinoma in cirrhotic patients with chronic hepatitis C. Gastroenterology 2011;140:1990-9.

16. Kwon H, Lok AS. Does antiviral therapy prevent hepatocellular carcinoma? Antivir Ther 2011;16:787-95.

17. http://www.cochrane.org/resources/handbook. 2011. Ref Type: Online Source. Accessed Aug 2012

18. Liberati A, Altman DG, Tetzlaff J, et al. The PRISMA statement for reporting systematic reviews and meta-analyses of studies that evaluate healthcare interventions: explanation and elaboration. $B M J$ 2009;339:b2700.

19. Wood L, Egger M, Gluud LL, et al. Empirical evidence of bias in treatment effect estimates in controlled trials with different interventions and outcomes: meta-epidemiological study. BMJ 2008;336:601-5.

20. Deeks J, Higgins PT. Statistical algorithms in Review Manager 5. 2010. Ref Type: Online Source. http://ims.cochrane.org/revman/ documentation/Statistical-methods-in-RevMan-5.pdf (accessed Aug 2012).

21. Higgins JP, Whitehead A, Simmonds M. Sequential methods for random-effects meta-analysis. Stat Med 2011;30:903-21.

22. Azzaroli F, Accogli E, Nigro G, et al. Interferon plus ribavirin and interferon alone in preventing hepatocellular carcinoma: a prospective study on patients with HCV related cirrhosis. World J Gastroenterol 2004;10:3099-102.

23. Bernardinello E, Cavalletto L, Chemello L, et al. Long-term clinical outcome after beta-interferon therapy in cirrhotic patients with 
chronic hepatitis C. TVVH Study Group. Hepatogastroenterology 1999;46:3216-22.

24. Fartoux L, Degos F, Trepo C, et al. Effect of prolonged interferon therapy on the outcome of hepatitis $C$ virus-related cirrhosis: a randomized trial. Clin Gastroenterol Hepatol 2007;5:502-7.

25. Lok AS, Everhart JE, Wright EC, et al. Maintenance peginterferon therapy and other factors associated with hepatocellular carcinoma in patients with advanced hepatitis C. Gastroenterology 2011;140:840-9.

26. Nishiguchi S, Shiomi S, Nakatani S, et al. Prevention of hepatocellular carcinoma in patients with chronic active hepatitis $C$ and cirrhosis. Lancet 2001;357:196-7.

27. Soga K, Shibasaki K, Aoyagi Y. Effect of interferon on incidence of hepatocellular carcinoma in patients with chronic hepatitis $\mathrm{C}$. Hepatogastroenterology 2005;52:1154-8.

28. Valla DC, Chevallier M, Marcellin P, et al. Treatment of hepatitis $C$ virus-related cirrhosis: a randomized, controlled trial of interferon alfa-2b versus no treatment. Hepatology 1999;29:1870-5.

29. Bruno $S$, Silini E, Crosignani $A$, et al. Hepatitis $C$ virus genotypes and risk of hepatocellular carcinoma in cirrhosis: a prospective study. Hepatology 1997;25:754-8.

30. Gramenzi A, Andreone P, Fiorino S, et al. Impact of interferon therapy on the natural history of hepatitis $C$ virus related cirrhosis. Gut 2001;48:843-8.
31. Mazzella G, Accogli E, Sottili S, et al. Alpha interferon treatment may prevent hepatocellular carcinoma in HCV-related liver cirrhosis. $J$ Hepatol 1996;24:141-7.

32. Serfaty L, Aumaitre $\mathrm{H}$, Chazouilleres $\mathrm{O}$, et al. Determinants of outcome of compensated hepatitis $\mathrm{C}$ virus-related cirrhosis. Hepatology 1998;27:1435-40.

33. Shiratori Y, Ito Y, Yokosuka O, et al. Antiviral therapy for cirrhotic hepatitis C: association with reduced hepatocellular carcinoma development and improved survival. Ann Intern Med 2005;142:105-14.

34. Goodgame B, Shaheen NJ, Galanko J, et al. The risk of end stage liver disease and hepatocellular carcinoma among persons infected with hepatitis $\mathrm{C}$ virus: publication bias? Am J Gastroenterol 2003;98:2535-42

35. Morgan TR, Ghany MG, Kim HY, et al. Outcome of sustained virological responders with histologically advanced chronic hepatitis C. Hepatology 2010;52:833-44.

36. Sanchez-Tapias JM, Diago M, Escartin P, et al. Peginterferon-alfa2a plus ribavirin for 48 versus 72 weeks in patients with detectable hepatitis $\mathrm{C}$ virus RNA at week 4 of treatment. Gastroenterology 2006;131:451-60.

37. Luth S, Schrader J, Zander S, et al. Chronic inflammatory IFN-gamma signaling suppresses hepatocarcinogenesis in mice by sensitizing hepatocytes for apoptosis. Cancer Res 2011;71:3763-71. 